\title{
Estimation of evapotranspiration from MODIS TOA radiances in the Poyang Lake basin, China
}

\author{
J. Peng ${ }^{1,2,3,4}$, Y. Liu ${ }^{1}$, X. Zhao ${ }^{1}$, and A. Loew $^{3}$ \\ ${ }^{1}$ State Key Laboratory of Lake Science and Environment, Nanjing Institute of Geography and Limnology, \\ Chinese Academy of Sciences, Nanjing 210008, China \\ ${ }^{2}$ Graduate University of Chinese Academy of Sciences, Beijing 100049, China \\ ${ }^{3}$ Max-Planck-Institute for Meteorology, KlimaCampus, 20146 Hamburg, Germany \\ ${ }^{4}$ International Max Planck Research School on Earth System Modelling, 20146 Hamburg, Germany
}

Correspondence to: Y. Liu (ybliu@niglas.ac.cn)

Received: 11 June 2012 - Published in Hydrol. Earth Syst. Sci. Discuss.: 27 September 2012

Revised: 22 February 2013 - Accepted: 18 March 2013 - Published: 15 April 2013

\begin{abstract}
Routine and rapid estimation of ET (evapotranspiration) at regional scale is of great significance for agricultural, hydrological and climatic studies. A simplified singlesource energy balance parameterization scheme, known as the LST/NDVI (land surface temperature/normalized difference vegetation index) triangle method, has been applied successfully to estimate regional clear sky ET in many studies. Based on the triangle method, we proposed a new method in this study to estimate daily ET directly using the TOA (top of atmosphere) radiances without performing atmospheric correction and other complicated processes. Firstly, the EF (evaporative fraction, defined as the ratio of latent heat flux to surface available energy) was estimated by interpolation in the LST/NDVI triangular-shaped scatter space, which was constructed using the MODIS (Moderate Resolution Imaging Spectroradiometer) TOA radiances over a heterogeneous area of the Poyang Lake basin in China. Then the net radiation over the same study area was derived based entirely on MODIS TOA radiances as well. Finally, daily ET maps were estimated from these EF maps and net radiation maps by using a sinusoidal temporal interpolation model. The estimated $\mathrm{EF}$, net radiation and ET have been validated against field observations collected for the period October 2007-July 2008. The results indicate comparable accuracy to results of other current widely used satellite-based methods. In addition, intercomparisons between the proposed method-based estimates and MODIS products-based estimates were also carried out over the validation site. The results suggest that the proposed method could reach similar level of accuracy as the
\end{abstract}

MODIS products-based triangle method. Overall, the proposed algorithm requires fewer assumptions and can avoid complex atmospheric corrections associated with the satellite derived products. It should facilitate direct use of satellite data for determining ET and relevant applications as well. Nonetheless, more validation work needs to be carried out with more integration of satellite data and ground-based measurements over various climatic regions and under different surface conditions in the future.

\section{Introduction}

ET (evapotranspiration), including plant transpiration and direct evaporation from soil and water surface, is an important variable in water and energy balances on the Earth's surface. Accurate estimation of the temporal and spatial distribution of ET is of great significance for better understanding the mechanism of climate change and plays a crucial role in the agricultural, hydrological and meteorology studies (Jung et al., 2010). The major factors that control the rate of ET are the availability of water, the amount of available energy, the wind speed and the humidity gradient in the air above the evaporating surface (Monteith, 1981). To account for all such factors, various micrometeorological techniques (e.g., Bowen ratio, eddy covariance and lysimeter systems) have been designed to measure ET on various spatial scales from hundreds to thousands of meters (Farahani et al., 2007). Although ET is quantifiable at the 
small scale using ground-based techniques, larger-scale estimates require alternative measurements and estimation approaches. They need a variety of land surface and atmospheric variables, such as temperature, albedo, and vegetation indices. Such quantities, however, are difficult to obtain over large-scale heterogeneous areas and have to be extrapolated/interpolated to various temporal and spatial scales with limited accuracy. Therefore, it is important and necessary to develop other methods for estimating regional ET.

Satellite remote sensing is a promising technique for mapping temporally and spatially continuous patterns of regional ET with a reasonable degree of accuracy. It can provide unprecedented spatial distribution of critical land surface and atmospheric variables, such as land surface temperature, albedo, and vegetation indices, which are logistically and economically impossible to obtain from conventional observation networks. Over the last few decades, a number of physical and empirical remote sensing based models that vary in complexity have been proposed to estimate ET. For a review, see e.g. Kalma et al. (2008). These methods usually need ancillary surface and atmospheric data like wind speed, aerodynamic resistance, and surface roughness, which cannot readily be measured through remote sensing techniques. Therefore, it is still challenging to routinely map regional and even global ET distribution using satellite remote sensing without ground measurements or reanalyzed meteorological data.

In order to overcome this problem, some attempts have been made to develop new parameterizations for ET estimation that depend entirely on remote sensing. One widely used approach among them is the LST/NDVI (land surface temperature/normalized difference vegetation index) triangle method, which was proposed by Jiang and Islam (1999). This method is based on the P-T (Priestley-Taylor) equation (Priestley and Taylor, 1972), which can be considered as a simplified version of the more general Penman equation (Penman, 1948). The most difficult part in this approach is the determination of the $\mathrm{P}-\mathrm{T}$ parameter, which accounts for aerodynamic and canopy resistances. The essence of the LST/NDVI triangle method is to estimate the $\mathrm{P}-\mathrm{T}$ parameter on the basis of the triangular shape of the LST/NDVI feature space, which is formed by the scatter of LST against NDVI over a wide range of soil moisture content and fractional vegetation cover. The emergence of the triangular shape is caused primarily by different sensitivity of LST to soil moisture variations over bare soil and vegetated areas. Recent and detailed reviews of the triangle method have been provided in terms of the theoretical basis, biophysical properties and limitations by Carlson (2007) and Petropoulos et al. (2009).

A number of researchers have also demonstrated the applicability of this method for the estimation of regional ET and soil moisture from various satellite sensors, such as NOAA-AVHRR (NOAA Advanced Very High Resolution Radiometer), TERRA/AQUA-MODIS, MSG-SEVIRI (Meteosat Second Generation-Spinning Enhanced Visible and
Infrared Imager) and FY-2C (FengYun-2C) (Han et al., 2010; Sandholt et al., 2002; Tang et al., 2011, among others). The notable advantages of this method lie in its simplicity, easiness to parameterize ET, and relatively high accuracy. The assessment of ET derived by the triangle method (Batra et al., 2006; Jiang and Islam, 2003; Jiang et al., 2004; Stisen et al., 2008; Long et al., 2012), shows that the root mean square difference (RMSD) and relative error (RE) are generally within $60 \mathrm{~W} \mathrm{~m}^{-2}$ and $30 \%$ at the hourly and daily timescales.

In general, the uncertainty associated with the estimation of ET could be attributed to many sources, one of which is the accuracy of the input satellite data products, such as LST, NDVI and albedo. However, these satellite derived variables are associated with a series of errors due to residual atmospheric effects, spatial and temporal resolution, viewing angles, etc. Since the triangle method is dependent on these variables, the uncertainties associated with the estimations of these variables will be accumulated and impact the accuracy of ET. Besides, the derivations of these variables rely on a series of steps in the processing chain, typically including angular modeling, atmospheric and radiative transfer correction. This poses a challenge to the remote sensing community in their effort to incorporate these processing procedures. In practice, these procedures are often complicated and increase the operational difficulty.

The objective of the present study is to develop an alternative scheme to estimate daily ET directly using the TOA (top of atmosphere) radiances without performing atmospheric correction and other processes. This idea stems from our earlier study that links TOA radiances with EF (evaporative fraction, defined as the ratio of latent heat flux to surface available energy) based on physical understanding of radiative transfer theory and Planck's law (Peng and Liu, 2011; Peng et al., 2012). Several earlier studies have also focused on the estimation of net surface shortwave and longwave radiation from measurements at the TOA (Tang et al., 2006; Wang et al., 2009), which significantly simplified the procedure and introduced relatively few sources of error. The method proposed here is based on the triangle method, utilizing the $\mathrm{EF}$ and net radiation schemes mentioned above to derive an instantaneous ET from the MODIS (Moderate Resolution Imaging Spectroradiometer) TOA radiances over a heterogeneous area of the Poyang Lake basin in China. A temporal interpolation scheme was subsequently implemented to produce a daily ET from our instantaneous estimates. To evaluate the performance of this new method, the estimates from the MODIS products were also derived based on the triangle method. Then both estimates were compared to a time series of ground-based measurements from Nanchang ecological experiment station in the Poyang Lake basin of China.

The paper is organized as follows: Sect. 2 presents the methodology and issues related to the retrieval of daily ET. Section 3 describes the data used in this study. Section 4 presents the results of implementing the proposed method over the study area for selected case days. Validations of the 
estimates against field observations are also discussed in this section. The conclusion is presented in Sect. 5 .

\section{Methodology for ET retrieval}

\subsection{Triangle method}

On the basis of spatial contextual information between land surface temperature and vegetation index, various methods have been proposed to retrieve soil water content, monitor drought conditions and analyze land use and land cover change (Carlson et al., 1995; Lambin and Ehrlich, 1996; Sun and Kafatos, 2007; Wan et al., 2004). The triangle method for ET by Jiang and Islam (1999) belongs to this category. It is named after the triangular or trapezoidal shape when plotting LST against NDVI (Fig. 1). The two boundaries of the LST/NDVI feature space constitute limiting conditions for the surface fluxes. The dry edge corresponding to higher temperatures represents minimum ET with unavailability of soil moisture for different vegetation indices. Here the surface temperature reaches a physical maximum where no evaporative cooling occurs. The wet edge corresponding to lower temperatures represents potential ET with unlimited soil water availability for different vegetation indices.

The implicit assumption of the triangle method is that ET primarily depends on soil moisture and vegetation cover. This assumption requires a heterogeneous area with a full range of possible soil moisture and vegetation fraction values, and at the same time relatively uniform atmospheric forcing (Margulis et al., 2005). For a detailed description and discussion of the LST/NDVI triangle feature space for ET estimation, the reader is referred to the work of Jiang and Islam (2001). On the basis of an extension of the P-T equation and the existence of a physically meaningful relationship between evaporative fraction and remotely sensed spatial variables (e.g., NDVI, LST and soil moisture), the parameterization of ET proposed by Jiang and Islam (1999) is expressed with the following equation:

$\mathrm{ET}=\varphi\left(\frac{\Delta}{\Delta+\gamma}\right)\left(R_{\mathrm{n}}-G\right)$.

Where ET is evapotranspiration $\left(\mathrm{W} \mathrm{m}^{-2}\right), R_{\mathrm{n}}$ is the surface net radiation $\left(\mathrm{W} \mathrm{m}^{-2}\right), G$ is the soil heat flux $\left(\mathrm{W} \mathrm{m}^{-2}\right), \Delta$ is the slope of saturated vapor pressure at the air temperature $\left(\mathrm{kPaK}^{-1}\right)$ and $\gamma$ is the psychrometric constant $\left(\mathrm{kPaK}^{-1}\right)$. $\Phi$ is a substitute for the $\mathrm{P}-\mathrm{T}$ coefficient, which accounts for aerodynamic and canopy resistances. In the standard application of the P-T method, $\Phi$ is approximately 1.26 for wet surface equilibrium conditions (Eichinger et al., 1996). In practice, $\Phi$, which is determined by wind speed, air temperature and surface moisture, should not be assigned to a constant value (Davies and Allen, 1973; Komatsu, 2003). It is important to note that in the absence of significant advection and convection, $\Phi$ in Eq. (1) can take a wider range of 0 (no ET)

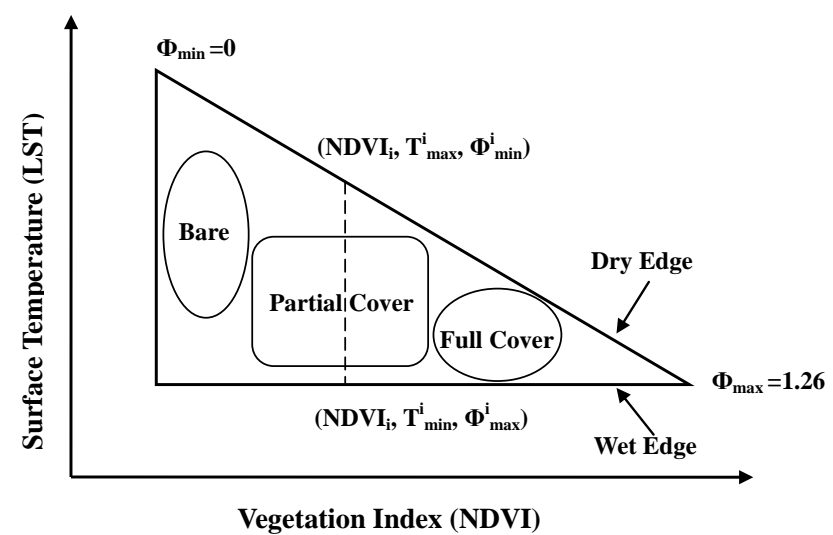

Fig. 1. Conceptual diagram of the LST/NDVI scatter plot to estimate evaporative fraction using wet and dry surfaces assumption. The dry (upper solid line) and wet (lower solid line) edges represent the maximum ET and minimum ET, respectively (after Tang et al., 2010; Lambin and Ehrlich, 1996; and Sandholt et al., 2002).

to $(\Delta+\gamma) / \Delta$ (maximum ET). This scheme is more applicable for a wide range of surface evaporative conditions where $R_{\mathrm{n}}-G$ is the driving force for ET.

In order to obtain the value of $\Phi$, a three-step linear interpolation scheme based on the LST/NDVI triangle is used in the following manner (see Fig. 1): (1) determine the dry and wet edges in the triangular space; (2) the global minimum and maximum $\Phi$ are respectively set to $\Phi_{\min }=0$ for the driest bare soil pixel and $\Phi_{\max }=1.26$ for the densely vegetated pixel with largest NDVI and lowest LST, then $\Phi_{\min }^{i}$ is linearly interpolated for each NDVI interval $\left(\mathrm{NDVI}_{i}\right)$ between $\Phi_{\min }$ and $\Phi_{\max }$, and $\Phi_{\max }^{i}$ for each $\mathrm{NDVI}_{i}$ that is obtained from the lowest LST pixel with that NDVI interval ( $\Phi_{\max }^{i}$ is generally set to $\Phi_{\max }^{i}=\Phi_{\max }=1.26$ ); (3) $\Phi^{i}$ value within each NDVI interval is interpolated between the lowest LST pixel $\left(T_{\min }^{i}, \Phi_{\max }^{i}\right)$, and highest LST pixel $\left(T_{\max }^{i}, \Phi_{\min }^{i}\right)$. Consequently, the $\Phi$ value for each pixel can be calculated using a normalized form of LST, and the mathematical expression is given as follows (Jiang and Islam, 2001):

$\Phi=\frac{T_{\max }^{i}-T^{i}}{T_{\max }^{i}-T_{\min }^{i}}\left(\Phi_{\max }^{i}-\Phi_{\min }^{i}\right)+\Phi_{\min }^{i}$.

The key procedure associated with the implementation of the above scheme is the accurate determination of the dry and wet edges. The wet edge (a horizontal line representing potential ET) is generally identified from the lowest surface temperature over different vegetation indices (Jiang and Islam, 2001). However, the dry edge (oblique line representing minimum ET) determination is a little subjective, which could incur uncertainty in the calculation of $\Phi$. Tang et al. (2010) proposed an automatically iterative process to determine the dry edge more objectively. This procedure is applied here to get the linear relation:

$T_{\max }^{i}=a+b \mathrm{NDVI}_{i}$, 
where $a$ and $b$ respectively define the intercept and slope of the dry edge.

According to Eq. (1) and the definition of EF, EF can be directly estimated as

$\mathrm{EF}=\Phi\left(\frac{\Delta}{\Delta+\gamma}\right)$.

The slope of saturated vapor pressure $\Delta$ at the air temperature $T_{\mathrm{a}}$ is given as

$\Delta=\frac{26297.76}{\left(T_{\mathrm{a}}-29.65\right)^{2}} \exp \left(\frac{17.67\left(T_{\mathrm{a}}-273.15\right)}{T_{\mathrm{a}}-29.65}\right)$.

The sensitivity of $\Delta /(\Delta+\gamma)$ on the variation of $T_{\mathrm{a}}$ is quite small with a reported $1-2 \%$ change per $1 \mathrm{~K}$ change in $T_{\mathrm{a}}$ (Jiang and Islam, 2001; Garatuza-Payan et al., 2001). Therefore, the $T_{\mathrm{a}}$ used in this equation can be obtained by using mean surface temperature or mean inland water surface temperature as a surrogate without incurring much error (Jiang and Islam, 2001; Tang et al., 2010). In this work, the MODIS MOD07 air temperature product (see Sect.3.2.2 for a description of MODIS products used in this study) will be used to provide spatially distributed $T_{\mathrm{a}}$, which is derived through a statistical relationship between observed TOA radiances and corresponding atmospheric profiles (Menzel et al., 2002).

The major advantages of the triangle method are that: (1) it holds true for a wide range of surface conditions; (2) it is relatively insensitive to uncertainties associated with atmospheric corrections and land surface heterogeneity; (3) all of the four quantities ( $\Phi, R_{\mathrm{n}}, G$, and $\Delta$ ) involved in Eq. (1) can be derived independently using remotely sensed data alone; (4) $\mathrm{EF}$ and $R_{\mathrm{n}}$ are estimated independently from each other, which provides the possibility to evaluate the performance of EF and $R_{\mathrm{n}}$ estimations respectively. The main limitation of the triangle method is that a large number of pixels over a flat area with a wide range of soil wetness and fractional vegetation cover are required to make sure that the dry and wet limits exist in the triangular space.

\subsection{Estimation of ET from MODIS products}

Instead of getting $T_{\mathrm{S}}$ and NDVI from in situ measurements, the parameters estimated from satellite data are used. In the following, MODIS products are used to derive ET

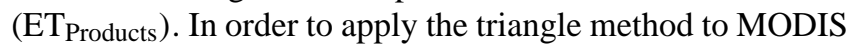
products, the EF and $R_{\mathrm{n}}$ will be estimated respectively. Several steps need to be carried out for EF calculation. As stated in Sect. 2.1, the LST/NDVI triangular space should be constructed firstly. The NDVI is calculated using the MOD09GA surface reflectance products after atmospheric correction, and LST is from the MODIS surface temperature product retrieved from MOD11 L2. Then, the wet and dry edges of the triangular space are determined using the algorithm described in Sect. 2.1. Finally, the EF value for each pixel in the study area is calculated from the triangular space.
$R_{\mathrm{n}}$, the sum of $R_{\mathrm{sn}}$ (shortwave net radiation) and $R_{\mathrm{ln}}$ (longwave net radiation), has to be estimated from satellite data. Here we employed the algorithm proposed by Bisht et al. (2005) for estimating $R_{\mathrm{n}}$ entirely from MODIS products. The method can be expressed as

$$
R_{\mathrm{n}}=R_{\mathrm{sn}}+R_{\mathrm{ln}}=(1-\alpha) \frac{S_{0} \cos ^{2} \theta}{d}+\sigma \varepsilon_{\mathrm{a}} T_{\mathrm{a}}^{4}-\sigma \varepsilon_{\mathrm{s}} T_{\mathrm{s}}^{4}
$$

with

$$
\begin{aligned}
d= & 1.085 \cos \theta+e_{0}(2.7+\cos \theta) \times 10^{-3}+0.1, \\
\varepsilon_{\mathrm{a}}= & {\left[1-(1+\xi) \exp \left\{-(1.2+3 \xi)^{1 / 2}\right\}\right], } \\
& \text { and } \xi=46.5 e_{0} / T_{\mathrm{a}} .
\end{aligned}
$$

Where $\alpha$ is the land surface albedo calculated from MOD43, $S_{0}$ is the solar constant at the atmospheric top $\left(1367 \mathrm{~W} \mathrm{~m}^{-2}\right)$, $\theta$ is the solar zenith angle extracted from MOD03, $\sigma$ is the Steffan-Boltzmann constant $\left(5.67 \times 10^{-8} \mathrm{~W} \mathrm{~m}^{-2} \mathrm{~K}^{-4}\right)$, $T_{\mathrm{a}}$ is the air temperature retrieved from MOD07, $\varepsilon_{\mathrm{S}}$ and $T_{\mathrm{S}}$ are the surface temperature and surface emissivity both extracted from MOD11 $\_2, e_{0}$ is the vapor pressure calculated from MOD07 dew point temperature by using the ClausiusClapeyron equation:

$e_{0}=6.11 \exp \left[\frac{L_{\mathrm{v}}}{R_{\mathrm{v}}}\left(\frac{1}{T_{0}}-\frac{1}{T_{\mathrm{d}}}\right)\right]$.

Where $L_{\mathrm{V}}$ is the latent heat of vaporization $\left(2.5 \times 10^{6} \mathrm{~J} \mathrm{~kg}^{-1}\right)$, $R_{\mathrm{V}}$ is the gas constant for water vapor $\left(461 \mathrm{~J} \mathrm{~kg}^{-1} \mathrm{~K}^{-1}\right), T_{\mathrm{d}}$ is the dew point temperature and $T_{0}=273 \mathrm{~K}$.

\subsection{Estimation of ET from MODIS TOA radiances}

In order to avoid certain difficulties associated with the processing chain for derivation of MODIS products, we directly used MODIS TOA radiances to estimate ET. The algorithm for estimating EF from MODIS TOA radiances is the same to the MODIS TOA products-based EF except for the input data source. About EF, Peng and Liu (2011) demonstrate the feasibility of using TOA radiances to estimate EF with the triangle method. Firstly, the TOA reflectance is used for calculating the TOA normalized difference vegetation index (NDVI $\mathrm{TOA}_{\mathrm{T}}$ ). It can be computed from the Level 1 MOD021KM and MOD03 datasets by converting the scaled integers (SI) to reflectance value with the following equation as given by (Toller et al., 2006)

$$
\begin{aligned}
\text { TOA_refectance }= & \text { reflectance_scale } \cdot(\mathrm{SI}- \\
& \text { reflectance_offset }) .
\end{aligned}
$$

Where the SI, reflectance_scale and reflectance_offset values are extracted from the MOD021KM head file, and $\theta$, the solar zenith angle, is extracted from the MOD03 dataset. Then 
NDVI $_{\text {TOA }}$ is calculated using the TOA reflectance values as follows:

$\mathrm{NDVI}_{\mathrm{TOA}}=\left(\rho_{\mathrm{NIR}}-\rho_{\mathrm{RED}}\right) /\left(\rho_{\mathrm{NIR}}+\rho_{\mathrm{RED}}\right)$.

Where $\rho_{\mathrm{NIR}}$ and $\rho_{\mathrm{RED}}$ are the TOA reflectances in the near infrared (NIR) and the red band from the MOD021KM dataset. The TOA radiance of the MODIS thermal infrared band $31\left(L_{31}\right)$ is used instead of the MODIS LST product. It is extracted using the following scaling equation:

TOA_radiance $=$ radiance_scale $\cdot(\mathrm{SI}-$ radiance_offset $)$.

With the SI, radiance_scale and radiance_offset values coming from the MOD021KM head file. Then, EF value for each pixel in the study area can be calculated using TOA reflectances and radiances as input.

The parameterization scheme for estimating $R_{\mathrm{n}}$ based on MODIS TOA radiances is different from the one applied to TOA MODIS products in Sect. 2.2. In this study, a parameterization of $R_{\mathrm{sn}}$ fully based on MODIS TOA radiances proposed by Tang et al. (2006) is used:

$R_{\mathrm{sn}}=\frac{E_{0} \cos \theta_{\mathrm{s}}}{D^{2}}\left(\alpha^{\prime}-\beta^{\prime} r\right)$,

$r=b_{0}+\sum_{i=1}^{7} b_{i} \rho_{i}$

Here $E_{0}$ is the solar irradiance at TOA, D is the earth-sun distance in astronomical unit. $\theta_{\mathrm{S}}$ is the solar zenith angle extracted from MOD03, $r$ is the broadband albedo at TOA, $\alpha$ ' and $\beta$ ' are parameters dependent on solar zenith angle and atmospheric precipitable water extracted from MOD05 over land surface, $\rho_{i}$ is the TOA reflectance in the MODIS band $i$ $(i=1-7)$ as provided in MOD021KM. $b_{0}-b_{7}$ are coefficients depending on the view zenith angle and the solar zenith angle, which are both retrieved from MOD03.

Similarly, Wang et al. (2009) and Wang and Liang (2009) developed a method to directly estimate the $R_{\ln }$ with merely MODIS TOA radiances as inputs:

$$
\begin{aligned}
R_{\mathrm{ln}}= & L_{T_{\mathrm{a}}}\left(a_{0}+a_{1} L_{27}+a_{2} L_{29}+a_{3} L_{33}+a_{4} L_{34}+\right. \\
& \left.b_{1} \frac{L_{32}}{L_{31}}+b_{2} \frac{L_{33}}{L_{32}}+b_{3} \frac{L_{28}}{L_{31}}+c_{1} H\right)+d_{0}+ \\
& d_{1} L_{31}+d_{2} L_{32}+d_{3} L_{29} .
\end{aligned}
$$

Here $L_{i}$ are the TOA radiances measured by the MODIS thermal infrared channel extracted from MOD021KM and the number in the subscript indicates the thermal channel of the MODIS sensor. $L_{T_{\mathrm{a}}}$ represents surface air temperature (equal to $L_{31}$ during nighttime and equal to $L_{32}$ during daytime). $a_{i}(i=0-4), b_{i}(i=1-3), \mathrm{c} 1$ and $d_{i}(i=0-3)$ are regression coefficients depending on the viewing zenith angle extracted from MOD03. $H$ is the surface elevation retrieved from MOD03. For detailed information about the above parameterizations of $R_{\mathrm{n}}$, readers are recommended to refer to relative papers.

\subsection{Estimation of daily ET}

The main objective of this work is to estimate ET on a daily scale, as daily ET is more applicable than instantaneous ET in hydrological and water resources management studies. However, the triangle method introduced above provides only instantaneous ET at the time of satellite overpass. In this work, we use the following scheme for extrapolating instantaneous ET values to a daily time step:

Firstly, the near noon instantaneous EF is used to represent the daily average EF value. This is based on observations (Caparrini et al., 2004; Crago, 1996) that for both homogeneous and heterogeneous land surfaces EF remains fairly constant for daylight hours, particularly between 10:00 LT and 16:00 LT. This can be explained from a physical perspective. The EF during daytime is mainly determined by land surface properties such as vegetation amount, soil moisture and surface resistance to heat and momentum transfer. Most of them are slowly varying parameters during daytime as compared to other fast changing variables (e.g., surface temperature, radiation), which have much stronger diurnal cycles due to radiation and atmospheric forcing (Jiang et al., 2009). Several studies have concluded that using local near noon EF instead of all-day EF for daily ET estimation incurs very small error (Farah et al., 2004; Hall et al., 1992; Hoedjes et al., 2008; Jia et al., 2009).

Secondly, daily $R_{\mathrm{n}}$ is estimated through a sinusoidal model (Bisht et al., 2005) that has been applied successfully in several studies (Bhattacharya et al., 2010; Bisht and Bras, 2010; Kim and Hogue, 2008). The sinusoidal model is given as

$R_{\mathrm{n}}^{\text {daily }}=\frac{\int_{t_{\text {rise }}}^{t_{\text {set }}} R_{\mathrm{n}}(t) \mathrm{d} t}{\int_{t_{\text {rise }}}^{t_{\text {set }}} \mathrm{d} t}=\frac{2 R_{\mathrm{n}}^{\text {overpass }}}{\pi \sin \left[\left(\frac{t_{\text {overpass }}-t_{\text {rise }}}{t_{\text {set }}-t_{\text {rise }}}\right) \pi\right]}$,

where $R_{\mathrm{n}}^{\text {overpass }}$ is the instantaneous $R_{\mathrm{n}}$ estimated at satellite overpass time, $t_{\text {rise }}, t_{\text {set }}, t_{\text {overpass }}$ denote local sunrise time, sunset time and satellite overpass time, respectively. Thus daily ET can be approximated as follows:

$\mathrm{ET}^{\text {daily }}=\left(R_{\mathrm{n}}^{\text {daily }}-G^{\text {daily }}\right) \mathrm{EF}^{\text {daily }}$.

It should be noted here that soil heat flux $G^{\text {daily }}$ is ignored in this study, as it is usually assumed negligible over the diurnal cycle (Jiang et al., 2009; Sánchez et al., 2008; Tang et al., 2011; Galleguillos et al., 2011). The above equation can thus be rewritten as

$\mathrm{ET}^{\text {daily }}=R_{\mathrm{n}}^{\text {daily }} \cdot \mathrm{EF}^{\text {daily }}$.

\subsection{Assessment strategy}

A two-step assessment strategy is applied to investigate the performance of the triangle method in the estimates of ET using TOA radiances $\left(\mathrm{ET}_{\mathrm{TOA}}\right)$. Firstly, the daily $\mathrm{ET}_{\mathrm{TOA}}$ is compared against in situ measurements. Since the estimation 


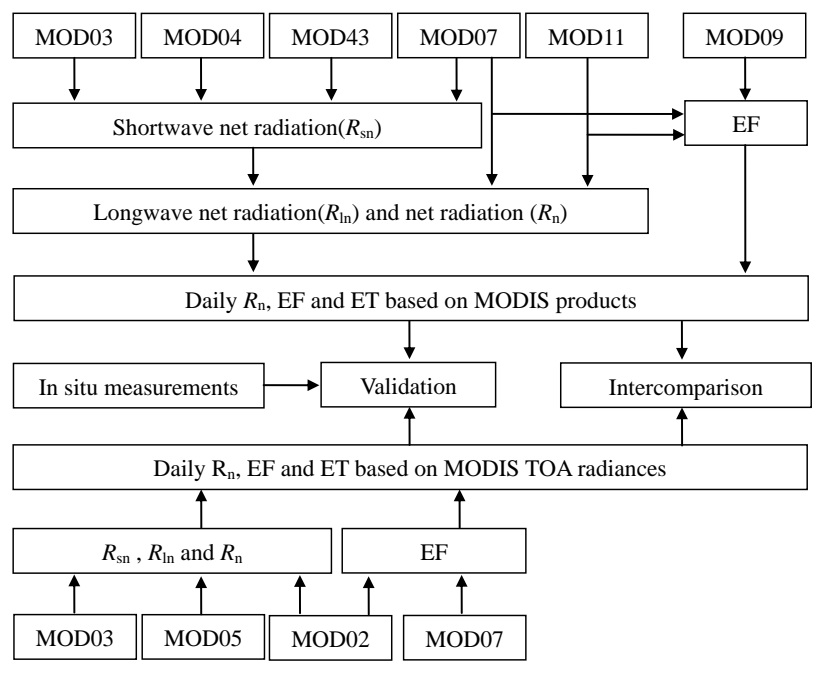

Fig. 2. Flowchart for the estimation of daily ET respectively from various MODIS products and the MODIS TOA radiances using the triangle method, and the validation of the satellite retrievals with in situ measurements.

of EF in this study is obviously independent of $R_{\mathrm{n}}$ estimation, the $\mathrm{EF}_{\mathrm{TOA}}, R_{\mathrm{n}_{-} \mathrm{TOA}}$ and $\mathrm{ET}_{\mathrm{TOA}}$ will be validated against in situ measurements, respectively. Then the intercomparisons between MODIS TOA radiances-based estimates and MODIS products-based estimates are carried out over the validation site. A flowchart is shown in Fig. 2 to illustrate the above strategy. A number of statistical indices, including mean bias error (BIAS), mean absolute difference (MAE), root mean square difference (RMSD), relative error (RE) and coefficient of the determination $\left(R^{2}\right)$ are chosen to evaluate the model performance in this study.

\section{Study area and data collection}

\subsection{Study area}

The study area in this work is located within the Poyang Lake basin of China, which lies on the southern bank of the middle and lower reaches of the Yangtze River. The domain is defined by latitude and longitude ranges $27.62-28.78^{\circ} \mathrm{N}$ and $114.51-116.95^{\circ} \mathrm{E}$, respectively. The surface elevation of most areas is approximately $10-200 \mathrm{~m}$ above the sea level. A mountainous region with average elevation of $1000 \mathrm{~m}$ above sea level lies in the northwestern part of the study region. Under the influence of the monsoon systems, the study area belongs to a humid subtropical climate zone. The annual mean air temperature and annual average precipitation based on observations during years $1951-2001$ were nearly $17.6^{\circ} \mathrm{C}$ and $1615 \mathrm{~mm}$, respectively. The annual rainfall over the study area occurs mainly during the humid summer months, with very little during spring and autumn, and much less during the cold, dry winters (Liu et al., 2010). Figure 3 shows the

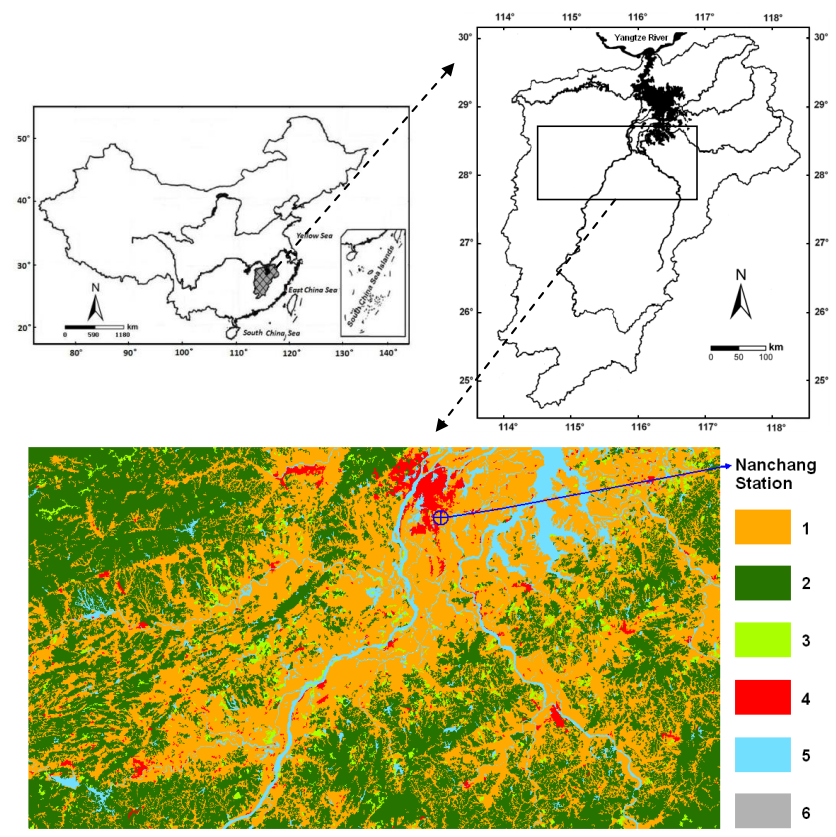

Fig. 3. Geographical location of the study area (up) and land cover map of the study area (down). Poyang Lake basin is located in the southeast of China and a relatively flat region within the basin is selected as our study area. The yearly land cover classification map in 2005 was provided by the Data sharing Network of Earth System Science, Chinese Academy of Sciences. 1=cropland, $2=$ forest, $3=$ grassland, $4=$ urban areas, $5=$ water, $6=$ bare soil. The location of the Nanchang ecological experimental station is also shown in the land cover map.

yearly land cover classification map in 2005 over the study area, provided by the Data sharing Network of Earth System Sciences, Chinese Academy of Sciences. It is a heterogeneous land cover area characterized by cropland (35\%), forest (45\%), grassland (3\%), urban areas (2\%), and inland water surface $(5 \%)$. Data used for validating the estimated $R_{\mathrm{n}}$, EF and ET are collected from Nanchang ecological experiment station (indicated in Fig. 3), which is located in the Nanchang County, Jiangxi Province. It is geographically situated at $28.6^{\circ} \mathrm{N}, 115.92^{\circ} \mathrm{E}$ at an elevation of $47 \mathrm{~m}$ above sea level. Land cover across the Nanchang station is grassland.

\subsection{Satellite data}

MODIS sensors were launched on board the National Aerodynamics and Space Administration (NASA) Earth Observing System (EOS) Terra and Aqua satellites on December 1999 and May 2002, respectively. With 36 discrete spectral bands ranging from visible, near-infrared, to thermal infrared and high spatial resolution at 250, 500, and $1000 \mathrm{~m}$, the MODIS sensor can provide data covering the entire surface of the Earth every 1 to 2 days. To date, the MODIS science team has developed 44 products for a variety of disciplines, including land, atmosphere, 
ocean and calibration. The Terra-MODIS Collection 5 data products used in this study consist of MOD021KM, MOD03, MOD04, MOD05L2, MOD07_L2, MOD09GA, MOD11_L2, MOD35_L2 and MOD43B3 (Table 1). A brief description of the data products used is given below. In order to validate and compare the estimation of ET, clear sky day images were selected on the basis of visual inspection of the MODIS true color image and the MOD35_L2 cloud mask product. We characterized $85 \%$ of the study area being clear as a clear sky condition, because it is difficult to avoid cloudy pixels over the whole domain. Finally, a total of 16 clear sky daytime MODIS data products ranging from fall to summer between 2007 and 2008 over our study area were used to estimate ET. The period from October 2007 to July 2008 was selected also because all the required satellite data and in situ measurements are both available during this period. Seven of the selected days are from 2007 (DOY: 277, 279, 283, 290, $300,327,332$ ) in 2007, and nine days are from 2008 (DOY: 003, 005, 061, 062, 084, 134, 138, 206, 209). During this study period, environmental conditions at the Nanchang station change considerably between dry and wet (see Fig. 6). Table 2 gives the description of selected days, satellite overpass time over the study region, and image quality for each day.

\subsubsection{MODIS TOA radiances}

TOA radiances for 36 bands were obtained from the MODIS Level 1B MOD021KM file, which is calibrated Earth View data at $1 \mathrm{~km}$ resolution from the MODIS Characterization and Support Team (MCST). The Level 1A MOD03 file consists of geolocation field data calculated for each $1 \mathrm{~km}$ MODIS instantaneous field of view (IFOV), including geodetic coordinates, ground elevation, and satellite zenith and azimuth angles for each $1 \mathrm{~km}$ pixel.

\subsubsection{MODIS products}

The MOD04_L2 aerosol product provides aerosol optical depth (AOD) on a $10 \mathrm{~km} \times 10 \mathrm{~km}$ pixel array (Remer et al., 2005). The MOD05_L2 product is the near-infrared total precipitable water data consisting of column water vapor amounts over clear land areas and above clouds over both land and ocean (King et al., 2003). The MOD07_L2 atmospheric profile product has a spatial resolution of $5 \times$ $5 \mathrm{~km}$ at 20 vertical atmospheric pressure levels, of which air and dew-point temperature were extracted from the vertical pressure level of $1000 \mathrm{hPa}$ (Bisht et al., 2005). The MOD09GA comprises of surface spectral reflectances from atmospheric correction, which are computed from MODIS Level 1B land bands 1-7 (Vermote and Kotchenova, 2008). The MOD11 L2 data contains LST and band-averaged emissivity in band-31 (10.780-11.280 $\mu \mathrm{m})$ and band-32 (11.770$12.270 \mu \mathrm{m})$ calculated using the generalized split-window algorithm (Wan and Dozier, 1996) at a spatial resolution of
$1 \mathrm{~km}$. The MOD35_L2 is a cloud mask product which assigns a clear-sky confidence level (clear, probably clear, uncertain, cloudy) to each IFOV (Frey et al., 2008). The MOD43B3 product provides clear-sky observations at $1 \mathrm{~km}$ spatial resolution for both Bidirectional Reflectance Distribution Function (BRDF) and albedo (Schaaf et al., 2002). Using the MODIS Reprojection Tool (MRT) and MODIS Reprojection Tool Swath (MRTSwath), all the MODIS data used in this work were transformed from HDF-EOS (Hierarchical Data Format-Earth Observation System) swath format to a Universal Transverse Mercator (UTM) projected GeoTIFF image and resampled for $1 \mathrm{~km}$ pixel size. It should be mentioned that all the above products are MODIS Level 2 data except land surface albedo, which is a global MODIS Level 3 data.

\subsection{Ground measurements}

A weighing lysimeter $\left(1 \mathrm{~m}^{2}\right.$ in area and $1 \mathrm{~m}$ in height $)$ at the Nanchang ecological experiment station has been set up to measure ET at a daily scale since August 2007 (Liu et al., 2010). The precision of the ET measurements is estimated to be $0.01 \mathrm{~mm}$ per day (Liu et al., 2010). The land cover across the Nanchang station is grassland, which relies on natural rainfall to grow and survive. Ground-measured surface net radiation, air temperature and rainfall were provided by the meteorology station, which is located only $30 \mathrm{~m}$ away from the lysimeter. The EF for the lysimeter is calculated as the ratio of the daily ET and daily net radiation.

\section{Results and discussion}

\subsection{Triangular scatter plots}

In order to calculate ET from MODIS products and MODIS TOA radiances for the case days, the dry and wet edges of the triangular space need to be determined firstly. This procedure is very important, because the uncertainty in the determination of the dry and wet edges will transfer to the estimation of EF and further affect the accuracy of estimated ET. Figure 4 gives examples of LST/NDVIProducts and TOA radiance/NDVI TOA $_{\text {scatter plots for five different representa- }}$ tive months over the seasons (October 2007, January 2008, March 2008, May 2008 and July 2008). As expected, January was characterized by low NDVI and low LST. From March to July, the NDVI and LST increased as the vegetation cover is increasing rapidly. In October both NDVI and LST decreased. The variations over different seasons show that both NDVI and LST rise first and then decline, reflecting the state of the soil moisture over the study area. When the soil moisture is low over the study area, the bare land surface is drying rapidly, and ET is small and absorption of the solar energy is mainly consumed for surface temperature. The absorption of the solar energy is mainly used for ET when the soil moisture is high. 
Table 1. MODIS data products used in this study and their characteristics as obtained from LAADS (Level 1 and Atmosphere Archive and Distribution Systems).

\begin{tabular}{|c|c|c|c|c|}
\hline MODIS data & Category & Version & $\begin{array}{l}\text { Spatial } \\
\text { resolution }\end{array}$ & Parameters used \\
\hline MOD021KM & Level 1B & 5 & $1 \mathrm{~km}$ & TOA radiance and reflectances \\
\hline MOD03 & Level 1A & 5 & $1 \mathrm{~km}$ & $\begin{array}{l}\text { Geodetic coordinates, ground elevation, } \\
\text { solar zenith and azimuth angles, } \\
\text { satellite zenith and azimuth angles }\end{array}$ \\
\hline MOD04 & Level 2 & 5 & $10 \mathrm{~km}$ & Aerosol optical depth \\
\hline MOD05 & Level 2 & 5 & $1 \mathrm{~km}$ & Column water vapor amounts \\
\hline MOD07 & Level 2 & 5 & $5 \mathrm{~km}$ & Air temperature and dew point temperature \\
\hline MOD09GA & Level 2 & 5 & $1 \mathrm{~km}$ & Surface reflectance after atmospheric correction \\
\hline MOD11 & Level 2 & 5 & $1 \mathrm{~km}$ & Surface emissivity and temperature \\
\hline MOD35 & Level 2 & 5 & $1 \mathrm{~km}$ & Cloud mask \\
\hline MOD43 & Level 3 & 5 & $1 \mathrm{~km}$ & Black- and white sky albedos \\
\hline
\end{tabular}

Table 2. Day of year, date, overpass time and image quality for the study days.

\begin{tabular}{llll}
\hline $\begin{array}{l}\text { Day of the } \\
\text { year (DOY) }\end{array}$ & Date & $\begin{array}{l}\text { Overpass time } \\
\text { (Local time) }\end{array}$ & $\begin{array}{l}\text { Image quality } \\
\text { (Cloud free pixels \%) }\end{array}$ \\
\hline 2007277 & 4 October 2007 & $11: 05$ & 96.74 \\
2007279 & 6 October 2007 & $10: 55$ & 96.00 \\
2007283 & 10 October 2007 & $10: 30$ & 93.62 \\
2007290 & 17 October 2007 & $10: 35$ & 92.73 \\
2007300 & 27 October 2007 & $11: 10$ & 99.19 \\
2007327 & 23 November 2007 & $10: 55$ & 97.64 \\
2007332 & 28 November 2007 & $11: 10$ & 98.99 \\
2008003 & 3 January 2008 & $10: 45$ & 96.09 \\
2008005 & 5 January 2008 & $10: 35$ & 94.80 \\
2008061 & 1 March 2008 & $11: 25$ & 98.24 \\
2008062 & 2 March 2008 & $10: 30$ & 95.23 \\
2008084 & 24 March 2008 & $11: 30$ & 95.90 \\
2008134 & 13 May 2008 & $11: 20$ & 92.37 \\
2008138 & 17 May 2008 & $10: 55$ & 91.91 \\
2008206 & 24 July 2008 & $10: 30$ & 88.50 \\
2008209 & 27 July 2008 & $11: 00$ & 97.11 \\
\hline
\end{tabular}

It can also be seen in Fig. 4 that the shapes of the TOA

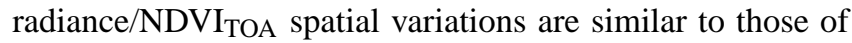
the LST/NDVIProducts spatial variations, which makes it possible to estimate comparable EF values from both datasets. The corresponding dry and wet edges of the triangular space were determined as described in the previous section. As shown in Fig. 4, they define the maximum and minimum envelopes of temperatures in the scatter plots. Table 3 illustrates the intercepts, slopes and the $R^{2}$ values for the dry edges of the LST/NDVI Products $_{\text {and TOA radiance/NDVI }}$ TOA scatter plots observed for the case days. One can see that the dry edge intercept in the LST/NDVI Products triangle varies from 286.54 to $316.62 \mathrm{~K}$, and from 7.61 to $10.94 \mathrm{~W} \mathrm{~m}^{-2} \mu \mathrm{m}^{-1} \mathrm{sr}^{-1}$ in the TOA radiance/NDVI ${ }_{\mathrm{TOA}}$ triangle. The dry edge slope also exhibited temporal variation ranging from -12.84 to $-2.65 \mathrm{~K}$ for $\mathrm{LST} / \mathrm{NDVI}_{\text {Products }}$ scatter plot, and from -2.83 to $-0.54 \mathrm{~W} \mathrm{~m}^{-2} \mu \mathrm{m}^{-1} \mathrm{sr}^{-1}$ for TOA radiance/NDVI ${ }_{\mathrm{TOA}}$ scatter plot throughout the study period. These variations of the parameters (slope and intercept) imply that a variety of hydrological conditions were present in the study period, and could capture the variability and direction of gradient in virtual surface dryness and wetness pattern. Furthermore, the high $R^{2}$ values, ranging from 0.921 to 0.988 for LST/NDVI Products triangular space and 0.88 to 0.998 for TOA radiance/NDVI $\mathrm{TOA}_{\mathrm{TO}}$ triangular space, indicate the reliability of the algorithm for determining the dry edge. Thus the uncertainty in the estimation of EF caused by the subjective determination of the dry edge will be significantly decreased.

\subsection{Evaporative fraction, daily net radiation and ET estimated from TOA Radiances}

In order to evaluate the accuracy of the estimated daily ET based on MODIS TOA radiances, ground measurements from Nanchang ecological experiment station are used as an independent data source for validation. Since EF and daily $R_{\mathrm{n}}$ are the key parameters in the estimation of ET and are calculated independently, their estimates from TOA radiances are evaluated before ET validation. In spite of the different spatial scales representative of satellite data and in situ data, $R_{\mathrm{n}}$ are believed to have very low spatial variability and validation of estimated $R_{\mathrm{n}}$ with ground-based measurements have been made in a variety of studies (Jin et al., 2011; Kim and Liang, 2010; Vinukollu et al., 2011). Daily $R_{\mathrm{n}}$ in this study is derived not by a complicated physicsbased model but through a simple sinusoidal model following the work of Bisht et al. (2005). Figure 5 shows the scatterplot of the derived daily $R_{\mathrm{n}}$ versus the observed $R_{\mathrm{n}}$ at Nanchang station for the sixteen case days in our study. Overall, good agreement between the estimated and measured $R_{\mathrm{n}}$ is obtained with BIAS $=13.11 \mathrm{~W} \mathrm{~m}^{-2}, \mathrm{RMSD}=20.47 \mathrm{~W} \mathrm{~m}^{-2}$ and $\mathrm{RE}=21.87 \%$ (Table 4). Furthermore, it can be observed that $R^{2}=0.931$. These statistics suggest the reliability of 

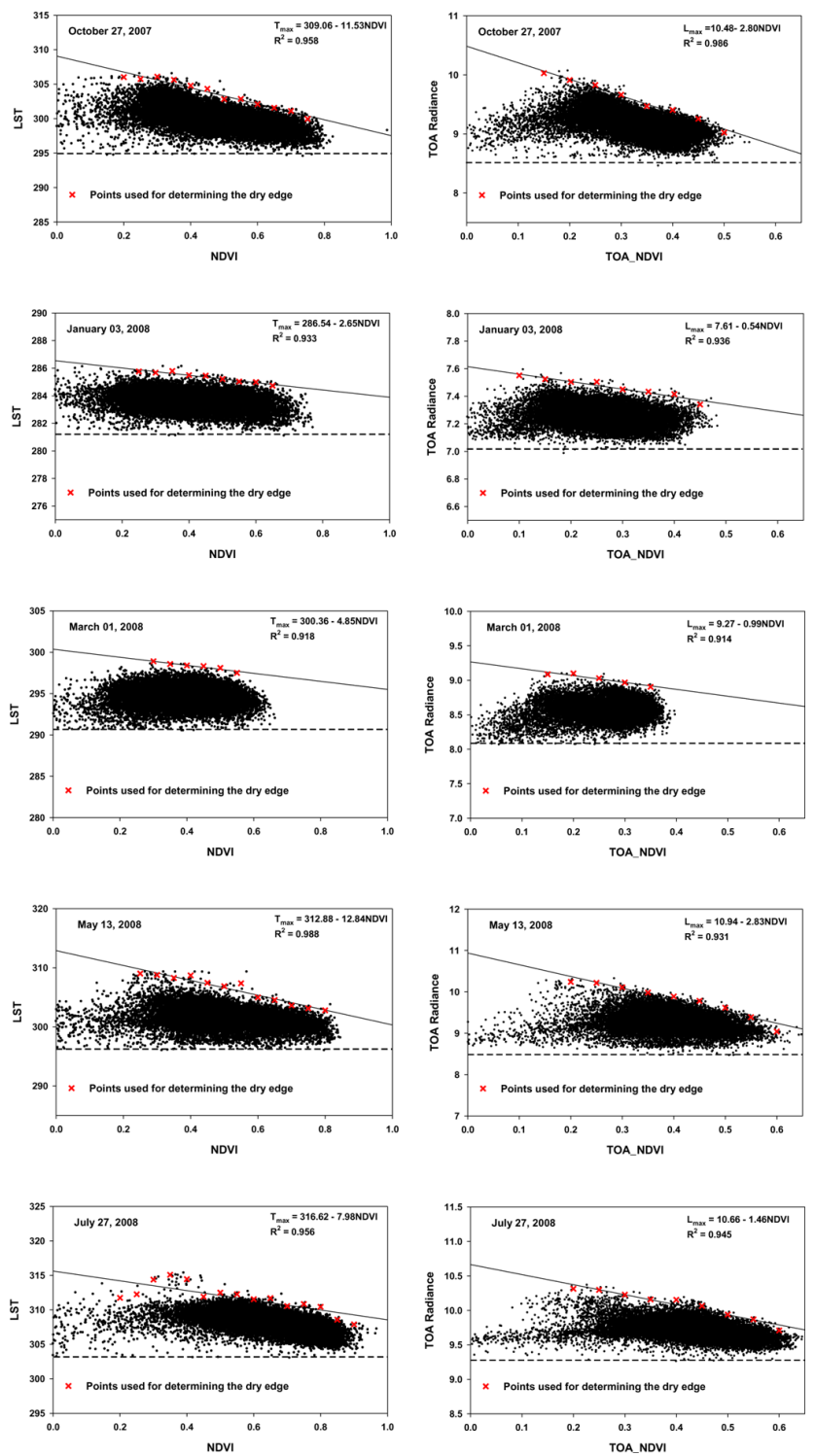

Fig. 4. Illustrative examples of LST/NDVI scatter plots constructed respectively from MODIS products and TOA radiances for five representative days over the study area during the study period.

deriving $R_{\mathrm{n}}$ with MODIS TOA radiances alone and the applicability of the sinusoidal model for estimating daily $R_{\mathrm{n}}$.

The next step is the evaluation of the EF estimate. It is worth nothing that the comparison of estimated EF with ground-measured data is essentially the true validation of the triangle method for ET estimate, as EF is a fairly conservative quantity over the course of a single day and is calculated entirely based on the LST/NDVI triangular feature space. Comparison between the MODIS TOA radiances-derived EF and in situ-measured EF is shown in Fig. 5. Statistics are also presented in Table 4. One can see from Fig. 5 that the derived EF agrees well with measured EF with a BIAS of -0.025 , RMSD of 0.064 , RE of $15.09 \%$, and $R^{2}$ of 0.559 .
Table 3. Statistics of the dry edge values used for estimation of EF ( $a$ and $b$ represent the intercept and slope of the dry edge respectively).

\begin{tabular}{llrrr}
\hline DOY & Scatter Plot & $a$ & $b$ & $R^{2}$ \\
\hline \multirow{2}{2}{007277} & NDVI-LST & 313.04 & -5.92 & 0.985 \\
& NDVI-TOA Radiance & 10.60 & -1.54 & 0.936 \\
2007279 & NDVI-LST & 311.26 & -7.39 & 0.931 \\
& NDVI-TOA Radiance & 10.73 & -2.11 & 0.88 \\
2007283 & NDVI-LST & 304.39 & -9.01 & 0.921 \\
& NDVI-TOA Radiance & 9.22 & -1.42 & 0.968 \\
2007290 & NDVI-LST & 304.02 & -8.61 & 0.934 \\
& NDVI-TOA Radiance & 9.85 & -2.58 & 0.965 \\
2007300 & NDVI-LST & 309.06 & -11.53 & 0.958 \\
& NDVI-TOA Radiance & 10.48 & -2.80 & 0.986 \\
2007327 & NDVI-LST & 297.91 & -4.92 & 0.957 \\
& NDVI-TOA Radiance & 9.07 & -1.16 & 0.907 \\
2007332 & NDVI-LST & 295.05 & -7.48 & 0.974 \\
& NDVI-TOA Radiance & 8.72 & -1.71 & 0.975 \\
2008003 & NDVI-LST & 286.54 & -2.65 & 0.933 \\
& NDVI-TOA Radiance & 7.61 & -0.54 & 0.936 \\
2008005 & NDVI-TOA Radiance & 7.98 & -0.85 & 0.978 \\
2008061 & NDVI-TOA Radiance & 9.27 & -0.99 & 0.914 \\
2008062 & NDVI-TOA Radiance & 9.15 & -1.86 & 0.998 \\
2008084 & NDVI-TOA Radiance & 9.15 & -0.68 & 0.974 \\
2008134 & NDVI-LST & 312.88 & -12.84 & 0.988 \\
& NDVI-TOA Radiance & 10.94 & -2.83 & 0.931 \\
2008138 & NDVI-LST & 314.46 & -6.03 & 0.938 \\
& NDVI-TOA Radiance & 10.70 & -1.03 & 0.896 \\
2008206 & NDVI-TOA Radiance & 9.47 & -0.56 & 0.910 \\
2008209 & NDVI-LST & 316.62 & -7.98 & 0.956 \\
& NDVI-TOA Radiance & 10.66 & -1.46 & 0.945 \\
\hline & & & & \\
\hline
\end{tabular}

The differences between the derived and measured EF may be attributed to the influence of topography (altitude and terrain orientation) (Carlson, 2007), the size of the domain, and the determination of the theoretical warm and wet edges (Long et al., 2012). Nevertheless, the results presented here are considered reasonable and satisfactory, given the simplicity of the method and the limited input requirements.

Similar evaluations of predictions of EF based on satellite products have been reported by other studies. Wang et al. (2006) estimated EF using MODIS products with a BIAS of -0.002 , RMSD of 0.106 and $R^{2}$ of 0.605 based on ground observations collected at the southern Great Plains of the United States. Stisen et al. (2008) obtained BIAS, RMSD and $R^{2}$ of $0.04,0.13$ and 0.63 , respectively, from the use of MSG-SEVIRI data products to derive EF in the Senegal River basin of West Africa. Another study validated over the North China Plain, using Fengyun-2C data products, reported BIAS, RMSD and $R^{2}$ of $-0.017,0.14$ and 0.55 , respectively (Shu et al., 2011). Some other methods may achieve higher accuracies, but they often need additional information from field observations, or the calibration against in situ measurements.

The final step is to examine the performance of the purely MODIS TOA radiances-based daily ET. The daily ET estimate is compared with ground-based daily ET. Results 
for the comparison are shown in Fig. 5 and statistics are provided in Table 4 . The BIAS of $0.132 \mathrm{~mm}$, RMSD of $0.292 \mathrm{~mm}, \mathrm{RE}$ of $23.28 \%$ and $R^{2}$ of 0.818 are achieved compared to measured values. This suggests that the proposed MODIS TOA radiances-based method performs well for estimating daily ET during clear sky days and the assumptions associated with the method are reasonable for the derivation of daily ET. As compared to EF validations, the results of daily ET show a slight improvement in terms of $R^{2}$. The reason for this is obviously caused by the inclusion of daily $R_{\mathrm{n}}$ in obtaining daily ET. Similar tendency was reported by Batra et al. (2006) and Jiang et al. (2009). The sources of errors in the estimation of daily ET originate from the uncertainties in both the estimated daily $R_{\mathrm{n}}$ and daily EF. However, it is difficult to further quantify the detailed error contribution from $R_{\mathrm{n}}$ and EF based on these limited analyses. In general, the RE of $23.28 \%$ in daily ET estimate is within the range of accuracies reported in the literature, between $15 \%$ and $30 \%$ (Kalma et al., 2008; Glenn et al., 2010; Verstraeten et al., 2008). The results presented above with BIAS $=0.132 \mathrm{~mm}$ and RMSD $=0.292 \mathrm{~mm}$ are comparable to other triangle method based ET estimation results elsewhere. Nishida et al. (2003) has validated MODIS-derived ET against AmeriFlux stations and achieved BIAS $=0.197 \mathrm{~mm}, \mathrm{RMSD}=1.587 \mathrm{~mm}$, and $R^{2}=0.86$. In the southern Great Plains of USA, different studies on ET estimation using NOAA-AVHRR and MODIS data obtained BIAS between -1.021 and $0.423 \mathrm{~mm}$, RMSE between 1.285 and $3.004 \mathrm{~mm}$, and $R^{2}$ between 0.47 and 0.89 (Batra et al., 2006; Jiang and Islam, 1999, 2001, 2003). Jiang et al. (2009) reported BIAS $=-0.151 \mathrm{~mm}, \mathrm{RMSD}=1.100 \mathrm{~mm}$, and correlation coefficient of 0.595 respectively from the comparison of NOAA-AVHRR data to multiyear ground observations over the South Florida region.

Figure 6 shows that the seasonal variation in estimated ET generally follows the rainfall and air temperature patterns. The high ET values appeared in wet periods with high air temperature, while the relatively low ET values occurred during dry seasons. The validation dataset with a temporal variation between dry and wet conditions further gives confidence that the MODIS TOA radiances-based estimates can provide reasonable results at other locations under different surface and meteorological conditions. As an example, the spatial distribution map of ET estimated from TOA radiances over the study area on 3 January 2008, is shown in Fig. 7. Comparing Fig. 7 and the land cover map in Fig. 3, one can see that areas covered by forests and water bodies in general have higher ET than other areas because of sufficient recharging of water resources from surface water or groundwater, while the lowest ET appeared in cropland due to no crops grown in the winter season. These distribution characteristics are in agreement with the spatial pattern of NDVI (Fig. 7), which is a measure of vegetation cover and crop growth condition.
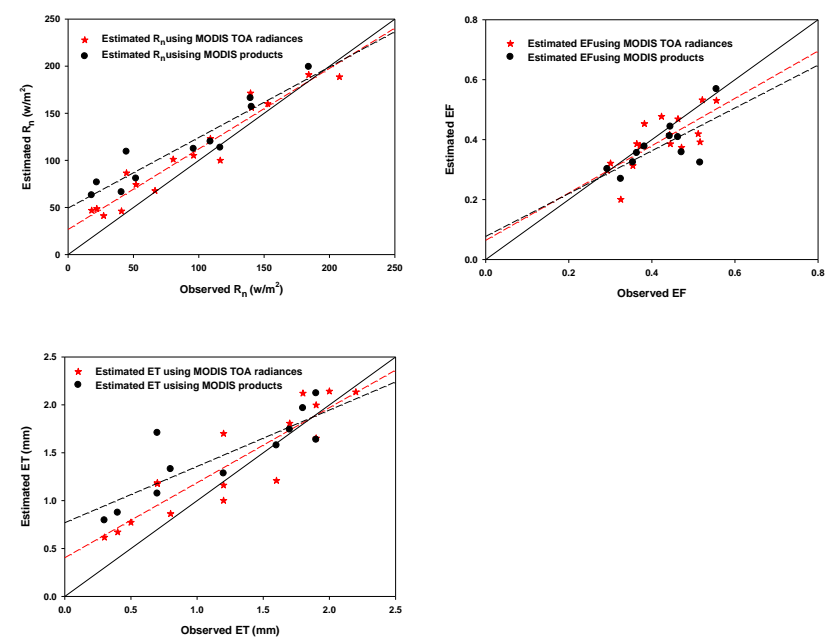

Fig. 5. Comparison of daily net radiation, evaporative fraction and ET estimated respectively from MODIS products and TOA radiances with field observations (data from Nanchang experimental station).

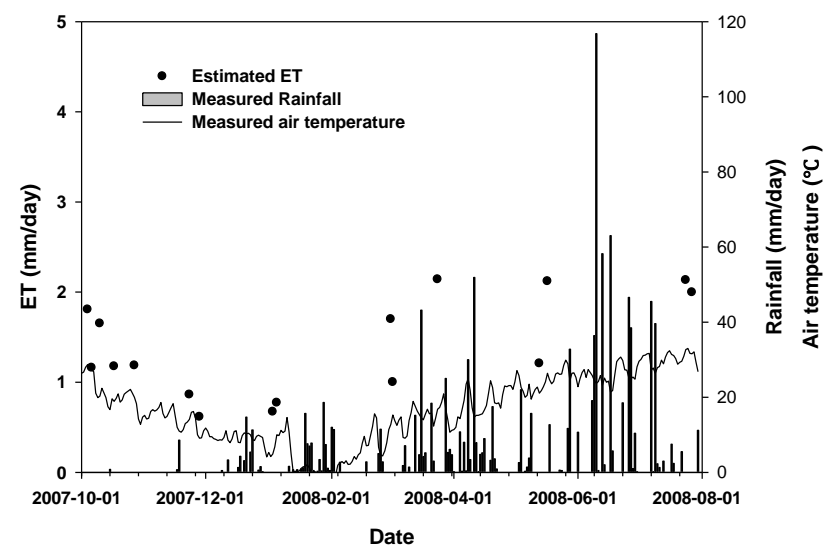

Fig. 6. Seasonal variation of estimated ET for Nanchang experimental station during the study period.

\subsection{Intercomparison of MODIS products and TOA radiances-based evaporative fraction, daily net radiation and ET}

The first step of our assessment strategy focused on the validation of the MODIS TOA radiances-based estimates against ground observations. It is also very interesting to analyze how MODIS TOA radiances-based estimations compare to retrievals based on MODIS products. Thus, the intercomparisons between these two estimates are carried out over the validation site in the second step. It should be noted here that 11 case days rather than all 16 case days were selected for the intercomparisons, as the MODIS LST products have no values over the validation site for five days. Actually, these five days are quite clear over the study area as depicted in Sect. 3.2. The void values in the LST products may be caused 
Table 4. Statistical results for the estimated $R_{\mathrm{n}}$, EF and ET using MODIS TOA radiances and MODIS products in comparison with observations at Nanchang station.

\begin{tabular}{lrrrlrrr}
\hline Parameter & BIAS & MAD & RMSD & Unit & $\begin{array}{r}\text { Relative } \\
\text { error (\%) }\end{array}$ & $R^{2}$ & $\begin{array}{r}\text { Number } \\
\text { of days }\end{array}$ \\
\hline$R_{\mathrm{n}}$ (TOA) & 13.11 & 17.55 & 20.47 & $\mathrm{~W} \mathrm{~m}^{-2}$ & 21.87 & 0.931 & 16 \\
$R_{\mathrm{n}}$ (TOA) & 16.88 & 19.87 & 22.69 & $\mathrm{~W} \mathrm{~m}^{-2}$ & 25.92 & 0.919 & 11 \\
$R_{\mathrm{n}}$ (Products) & 27.38 & 27.89 & 33.38 & $\mathrm{~W} \mathrm{~m}^{-2}$ & 38.13 & 0.892 & 11 \\
EF (TOA) & -0.025 & 0.049 & 0.064 & & 15.09 & 0.559 & 16 \\
EF (TOA) & -0.036 & 0.055 & 0.069 & & 16.48 & 0.553 & 11 \\
EF (Products) & -0.043 & 0.047 & 0.073 & & 17.30 & 0.512 & 11 \\
ET (TOA) & 0.132 & 0.250 & 0.292 & $\mathrm{~mm}$ & 23.28 & 0.818 & 16 \\
ET (TOA) & 0.133 & 0.256 & 0.300 & $\mathrm{~mm}$ & 25.26 & 0.800 & 11 \\
ET (Products) & 0.283 & 0.335 & 0.433 & $\mathrm{~mm}$ & 36.64 & 0.716 & 11 \\
\hline
\end{tabular}
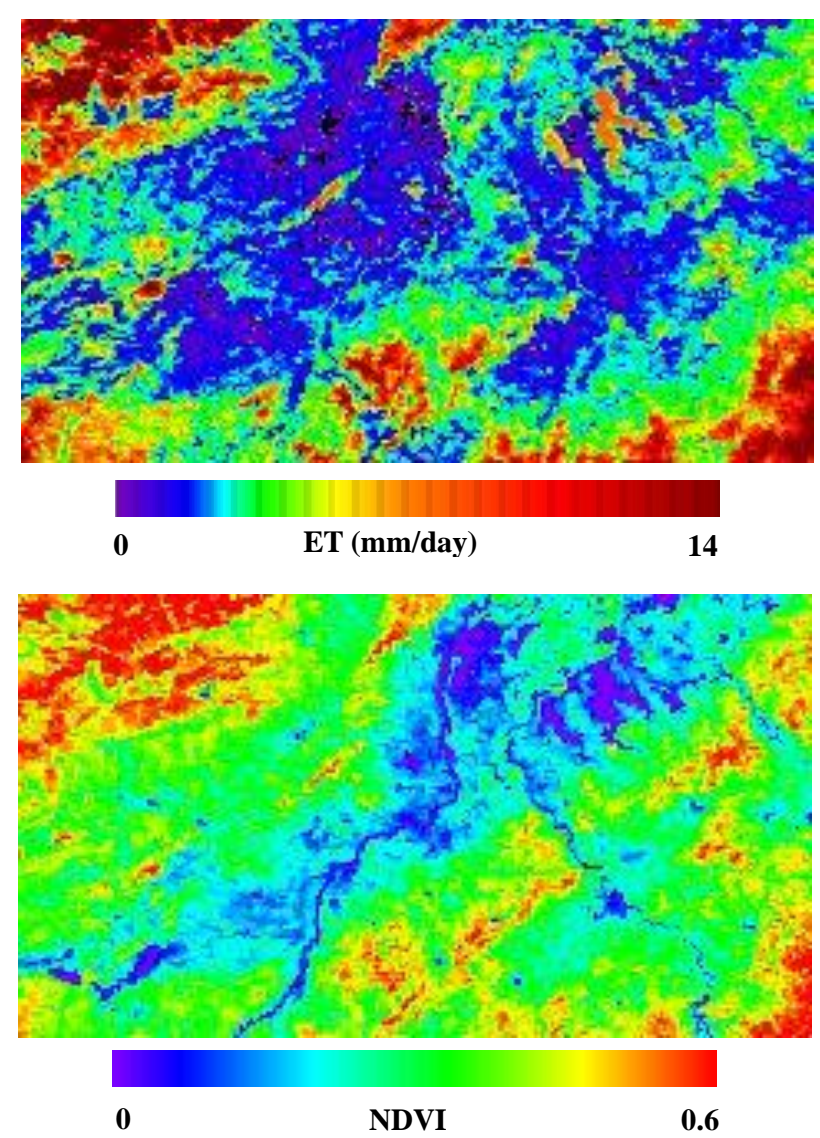

Fig. 7. Spatial distribution of daily ET (top) and NDVI (bottom) maps at $1 \mathrm{~km}$ resolution for 3 January 2008 over the study area.

by misclassification of the MODIS cloud mask product. It further addresses the advantage of using TOA radiances directly to estimate $R_{\mathrm{n}}, \mathrm{EF}$ and ET. The validation exercise provided similar results for the TOA radiances-based and products-based estimates of the daily $R_{\mathrm{n}}$, EF and ET when assessing from a visual inspection, as displayed in Fig. 5. Corresponding statistics were summarized in Table 4. For
TOA radiances-based estimates, the RE for daily $R_{\mathrm{n}}$, EF and ET were less than $30 \%$. The magnitude of this error is within the range for remote sensing based parameterization schemes. As stated previously, the general uncertainty in the estimation of heat fluxes is in the $15-30 \%$ range. The accuracy of $R_{\mathrm{n}}$ and EF are also in the same order of magnitude (Bisht et al., 2005; Jiang et al., 2004; Stisen et al., 2008). Validation results for products-based estimates were worse, with RE for daily $R_{\mathrm{n}}$ and ET both slightly higher than $30 \%$. Overall, the TOA radiances-based estimates performed better than the products-based estimates, because the BIAS and RMSD for daily $R_{\mathrm{n}}, \mathrm{EF}$ and ET are lower than the former, and the $R^{2}$ values higher than the former. The above results further suggest that the TOA radiances-based method is operationally feasible and can provide reasonable estimation accuracy for daily ET.

The discrepancies between the estimates and the measurements might be related to the differences in spatial scales between the satellite area integrated value and the field point measurement, and the heterogeneity of the land surface within the satellite footprint (Kustas et al., 2004; McCabe and Wood, 2006; Vinukollu et al., 2011). As depicted in Sect. 1 , the lysimeter $\left(1 \mathrm{~m}^{2}\right)$ is located in homogeneous land cover, while the satellite has a footprint of $1 \mathrm{~km}$. This incompatibility in spatial scale will evidently introduce uncertainty in the comparative analysis.

An improved option to further investigate the importance of scale issues is using flux tower data for additional comparisons, as the tower fluxes represent a footprint of roughly 1-3 km (Cleugh et al., 2007; Running et al., 1999), which we plan for the future. The validation of the proposed method against flux tower footprint measurements over various climatic regions and analysis of the uncertainties associated with the comparison will be the focus of our subsequent research. 


\section{Conclusions}

Recently, various attempts have been made to estimate regional ET by using remote sensing derived products. However the derivations of these variables are composed of a series of processing steps. Errors associated with each step may be accumulated and finally impact the accuracy of these variables. Further, these uncertainties will be transferred to the estimation of ET. In this study, we proposed a method to estimate daily ET directly using TOA radiances, which attempted to overcome the limitations related to using satellite derived variables. It eliminated the complex processing chain of deriving these variables and provided a useful alternative for determining ET from satellite data. The proposed method was derived through the following procedures. Firstly, the instantaneous EF and $R_{\mathrm{n}}$ were calculated from MODIS TOA radiances, respectively. Then, daily ET were estimated based on these EF and $R_{\mathrm{n}}$ estimates by using a sinusoidal temporal interpolation model.

The proposed method was tested in the Poyang Lake basin for sixteen case days between October 2007 and July 2008. The field observations collected for the same period were used to validate the estimated EF, $R_{\mathrm{n}}$ and ET. The results are promising and appear to provide comparable or better estimates than currently available satellite-based methods, given the common uncertainties in $R_{\mathrm{n}}, \mathrm{EF}$ and ET. In addition, the intercomparisons between the proposed method-based estimates and MODIS products-based estimates were also carried out over the validation site. The results suggested that the proposed method achieved similar accuracy as the MODIS products-based triangle method, which further confirmed the feasibility of the proposed method for ET estimation. Consequently, we believe that the use of TOA radiances appears to be adequate for the estimation of daily ET in conjunction with the triangle method over large areas under the assumption of uniform atmospheric forcings.

The uncertainty in our MODIS TOA radiances-based estimates may be attributed to the incompatibility in spatial scale between satellite footprint and ground-based point measurement. This requires us to further explore more feasible comparison metrics for the validation of the remote sensing estimates using field observations. In addition, to make the proposed method more general and operational for the estimation of daily ET, in the future, more validation work needs to be carried out with more integration of satellite data and ground-based measurements over various climatic regions and under different surface conditions.

Acknowledgements. This work was partly supported by the Cluster of Excellence CliSAP (EXC177), University of Hamburg, funded through the German Science Foundation (DFG) and by the CAS-MPG Doctoral Promotion Programme (DPP). The MODIS Level 1 and Level 2 datasets are downloaded from the Level 1 and Atmosphere Archive and Distribution System (LAADS, http://ladsweb.nascom.nasa.gov/). The MODIS Level 3 datasets are obtained in the next generation metadata and service discovery tool (Reverb, http://reverb.echo.nasa.gov/reverb/). The authors would like to thank Zhang Qi for providing the lysimeter data and the China Meteorological Administration for supporting the climatic data. The authors would like to thank Editor Niko Verhoest, and Reviewer Carlos Jiménez and an anonymous reviewer for their valuable comments and suggestions.

The service charges for this open access publication have been covered by the Max Planck Society.

Edited by: N. Verhoest

\section{References}

Batra, N., Islam, S., Venturini, V., Bisht, G., and Jiang, L.: Estimation and comparison of evapotranspiration from MODIS and AVHRR sensors for clear sky days over the Southern Great Plains, Remote Sens. Environ., 103, 1-15, doi:10.1016/j.rse.2006.02.019, 2006.

Bhattacharya, B. K., Mallick, K., Patel, N. K., and Parihar, J. S.: Regional clear sky evapotranspiration over agricultural land using remote sensing data from Indian geostationary meteorological satellite, J. Hydrol., 387, 65-80, doi:10.1016/j.jhydrol.2010.03.030, 2010.

Bisht, G. and Bras, R. L.: Estimation of net radiation from the MODIS data under all sky conditions: Southern Great Plains case study, Remote Sens. Environ., 114, 1522-1534, doi:10.1016/j.rse.2010.02.007, 2010.

Bisht, G., Venturini, V., Islam, S., and Jiang, L.: Estimation of the net radiation using MODIS (Moderate Resolution Imaging Spectroradiometer) data for clear sky days, Remote Sens. Environ., 97, 52-67, doi:10.1016/j.rse.2005.03.014, 2005.

Caparrini, F., Castelli, F., and Entekhabi, D.: Estimation of Surface Turbulent Fluxes through Assimilation of Radiometric Surface Temperature Sequences, J. Hydrometeorol., 5, 145-159, doi:10.1175/1525-7541(2004)005<0145:eostft >2.0.co;2, 2004.

Carlson, T. N.: An overview of the "triangle method" for estimating surface evapotranspiration and soil moisture from satellite imagery, Sensors, 7, 1612-1629, doi:10.3390/s7081612, 2007.

Carlson, T. N., Gillies, R. R., and Schmugge, T. J.: An interpretation of methodologies for indirect measurement of soil water content, Agr. Forest Meteorol., 77, 191-205, 1995.

Cleugh, H. A., Leuning, R., Mu, Q., and Running, S. W.: Regional evaporation estimates from flux tower and MODIS satellite data, Remote Sens. Environ., 106, 285-304, doi:10.1016/j.rse.2006.07.007, 2007.

Crago, R. D.: Conservation and variability of the evaporative fraction during the daytime, J. Hydrol., 180, 173-194, doi:10.1016/0022-1694(95)02903-6, 1996.

Davies, J. A. and Allen, C. D.: Equilibrium, Potential and Actual Evaporation from Cropped Surfaces in Southern Ontario, J. Appl. Meteorol., 12, 649-657, doi:10.1175/15200450(1973)012<0649:epaaef>2.0.co;2, 1973.

Eichinger, W. E., Parlange, M. B., and Stricker, H.: On the Concept of Equilibrium Evaporation and the Value of the Priestley-Taylor Coefficient, Water Resour. Res., 32, 161-164, doi:10.1029/95wr02920, 1996. 
Farah, H., Bastiaanssen, W., and Feddes, R.: Evaluation of the temporal variability of the evaporative fraction in a tropical watershed, Int. J. Appl. Earth Obs. Geoinf., 5, 129-140, 2004.

Farahani, H. J., Howell, T. A., Shuttleworth, W. J., and Bausch, W. C.: Evapotranspiration: Progress in measurement and modeling in agriculture, T. Asabe, 50, 1627-1638, 2007.

Frey, R. A., Ackerman, S. A., Liu, Y., Strabala, K. I., Zhang, H., Key, J. R., and Wang, X.: Cloud detection with MODIS. Part I: Improvements in the MODIS cloud mask for collection 5, J. Atmos. Ocean. Tech., 25, 1057-1072, 2008.

Galleguillos, M., Jacob, F., Prévot, L., French, A., and Lagacherie, P.: Comparison of two temperature differencing methods to estimate daily evapotranspiration over a Mediterranean vineyard watershed from ASTER data, Remote Sens. Environ., 115, 13261340, doi:10.1016/j.rse.2011.01.013, 2011.

Garatuza-Payan, J., Pinker, R. T., Shuttleworth, W. J., and Watts, C. $\mathrm{J}$. : Solar radiation and evapotranspiration in northern Mexico estimated from remotely sensed measurements of cloudiness, Hydrolog. Sci. J., 46, 465-478, doi:10.1080/02626660109492839, 2001.

Glenn, E., Nagler, P., and Huete, A.: Vegetation Index Methods for Estimating Evapotranspiration by Remote Sensing, Surv. Geophys., 31, 531-555, doi:10.1007/s10712-010-9102-2, 2010.

Hall, F. G., Huemmrich, K. F., Goetz, S. J., Sellers, P. J., and Nickeson, J. E.: Satellite Remote Sensing of Surface Energy Balance: Success, Failures, and Unresolved Issues in FIFE, J. Geophys. Res., 97, 19061-19089, doi:10.1029/92jd02189, 1992.

Han, Y., Wang, Y., and Zhao, Y.: Estimating soil moisture conditions of the greater Changbai Mountains by land surface temperature and NDVI, IEEE T. Geosci. Remote Sens., 48, 2509-2515, 2010.

Hoedjes, J., Chehbouni, A., Jacob, F., Ezzahar, J., and Boulet, G.: Deriving daily evapotranspiration from remotely sensed instantaneous evaporative fraction over olive orchard in semi-arid Morocco, J. Hydrol., 354, 53-64, 2008.

Jia, L., Xi, G., Liu, S., Huang, C., Yan, Y., and Liu, G.: Regional estimation of daily to annual regional evapotranspiration with MODIS data in the Yellow River Delta wetland, Hydrol. Earth Syst. Sci., 13, 1775-1787, doi:10.5194/hess-13-17752009, 2009.

Jiang, L. and Islam, S.: A methodology for estimation of surface evapotranspiration over large areas using remote sensing observations, Geophys. Res. Lett., 26, 2773-2776, 1999.

Jiang, L. and Islam, S.: Estimation of surface evaporation map over southern Great Plains using remote sensing data, Water Resour. Res., 37, 329-340, 2001.

Jiang, L. and Islam, S.: An intercomparison of regional latent heat flux estimation using remote sensing data, Int. J. Remote Sens., 24, 2221-2236, doi:10.1080/01431160210154821, 2003.

Jiang, L., Islam, S., and Carlson, T. N.: Uncertainties in latent heat flux measurement and estimation: implications for using a simplified approach with remote sensing data, Can. J. Remote Sens., 30, 769-787, doi:10.5589/m04-038, 2004.

Jiang, L., Islam, S., Guo, W., Singh Jutla, A., Senarath, S. U. S., Ramsay, B. H., and Eltahir, E.: A satellitebased Daily Actual Evapotranspiration estimation algorithm over South Florida, Global Planet. Change, 67, 62-77, doi:10.1016/j.gloplacha.2008.12.008, 2009.
Jin, Y., Randerson, J. T., and Goulden, M. L.: Continental-scale net radiation and evapotranspiration estimated using MODIS satellite observations, Remote Sens. Environ., 115, 2302-2319, 2011.

Jung, M., Reichstein, M., Ciais, P., Seneviratne, S. I., Sheffield, J., Goulden, M. L., Bonan, G., Cescatti, A., Chen, J., and de Jeu, R.: Recent decline in the global land evapotranspiration trend due to limited moisture supply, Nature, 467, 951-954, 2010.

Kalma, J., McVicar, T., and McCabe, M.: Estimating Land Surface Evaporation: A Review of Methods Using Remotely Sensed Surface Temperature Data, Surveys in Geophysics, 29, 421-469, doi:10.1007/s10712-008-9037-z, 2008.

Kim, H.-Y. and Liang, S.: Development of a hybrid method for estimating land surface shortwave net radiation from MODIS data, Remote Sens. Environ., 114, 2393-2402, doi:10.1016/j.rse.2010.05.012, 2010.

Kim, J. and Hogue, T. S.: Evaluation of a MODIS-Based Potential Evapotranspiration Product at the Point Scale, J. Hydrometeorol., 9, 444-460, doi:10.1175/2007jhm902.1, 2008.

King, M. D., Menzel, W. P., Kaufman, Y. J., Tanré, D., Gao, B. C., Platnick, S., Ackerman, S. A., Remer, L. A., Pincus, R., and Hubanks, P. A.: Cloud and aerosol properties, precipitable water, and profiles of temperature and water vapor from MODIS, IEEE T. Geosci. Remote Sens., 41, 442-458, 2003.

Komatsu, T. S.: Toward a Robust Phenomenological Expression of Evaporation Efficiency for Unsaturated Soil Surfaces, J. Appl. Meteorol., 42, 1330-1334, doi:10.1175/15200450(2003)042<1330:tarpeo > 2.0.co;2, 2003.

Kustas, W. P., Li, F., Jackson, T. J., Prueger, J. H., MacPherson, J. I., and Wolde, M.: Effects of remote sensing pixel resolution on modeled energy flux variability of croplands in Iowa, Remote Sens. Environ., 92, 535-547, doi:10.1016/j.rse.2004.02.020, 2004.

Lambin, E. F. and Ehrlich, D.: The surface temperature-vegetation index space for land cover and land-cover change analysis, Int. J. Remote Sens., 17, 463-487, doi:10.1080/01431169608949021, 1996.

Liu, B., Jiang, T., Zhai, J., and Zhang, W.: New Design and Observation of Lysimeter on Actual Evapotranspiration, Meteorological Monthly, 36, 112-116, doi:10.1002/hyp.8341, 2010 (in Chinese).

Long, D., Singh, V. P., and Scanlon, B. R.: Deriving theoretical boundaries to address scale dependencies of triangle models for evapotranspiration estimation, J. Geophys. Res. Atmos., 117, D05113, doi:10.1029/2011jd017079, 2012.

Margulis, S. A., Kim, J., and Hogue, T.: A Comparison of the Triangle Retrieval and Variational Data Assimilation Methods for Surface Turbulent Flux Estimation, J. Hydrometeorol., 6, 10631072, doi:10.1175/jhm451.1, 2005.

McCabe, M. F. and Wood, E. F.: Scale influences on the remote estimation of evapotranspiration using multiple satellite sensors, Remote Sens. Environ., 105, 271-285, doi:10.1016/j.rse.2006.07.006, 2006.

Menzel, W. P., Seemann, S. W., Li, J., and Gumley, L. E.: MODIS atmospheric profile retrieval algorithm theoretical basis document, University of Wisconsin-Madison, 2002.

Monteith, J. L.: Evaporation and surface temperature, Q. J. Roy. Meteorol. Soc., 107, 1-27, doi:10.1002/qj.49710745102, 1981.

Nishida, K., Nemani, R. R., Running, S. W., and Glassy, J. M.: An operational remote sensing algorithm of land surface evapora- 
tion, J. Geophys. Res., 108, 4270, doi:10.1029/2002JD002062, 2003.

Peng, J. and Liu, Y.: Estimation of evaporative fraction from top-ofatmosphere radiance, IAHS-AISH P., 343, 47-52, 2011.

Peng, J., Liu, Y., and Loew, A.: Uncertainties in estimating Normalized Difference Temperature Index from TOA radiances, IEEE T. Geosci. Remote Sens., online first, doi:10.1109/TGRS.2012.2213603, 2012.

Penman, H. L.: Natural evaporation from open water, bare soil and grass, P. Roy. Soc. London Ser. A, 193, 120-145, 1948.

Petropoulos, G., Carlson, T., Wooster, M., and Islam, S.: A review of Ts/VI remote sensing based methods for the retrieval of land surface energy fluxes and soil surface moisture, Progr. Phys. Geogr., 33, 224-250, 2009.

Priestley, C. and Taylor, R.: On the assessment of surface heat flux and evaporation using large-scale parameters, Mon. Weather Rev., 100, 81-92, 1972.

Remer, L. A., Kaufman, Y. J., Tanré, D., Mattoo, S., Chu, D. A., Martins, J. V., Li, R. R., Ichoku, C., Levy, R. C., Kleidman, R. G., Eck, T. F., Vermote, E., and Holben, B. N.: The MODIS Aerosol Algorithm, Products, and Validation, J. Atmos. Sci., 62, 947-973, doi:10.1175/jas3385.1, 2005.

Running, S. W., Baldocchi, D. D., Turner, D. P., Gower, S. T., Bakwin, P. S., and Hibbard, K. A.: A Global Terrestrial Monitoring Network Integrating Tower Fluxes, Flask Sampling, Ecosystem Modeling and EOS Satellite Data, Remote Sens. Environ., 70, 108-127, doi:10.1016/s0034-4257(99)00061-9, 1999.

Sánchez, J. M., Scavone, G., Caselles, V., Valor, E., Copertino, V. A., and Telesca, V.: Monitoring daily evapotranspiration at a regional scale from Landsat-TM and ETM+ data: Application to the Basilicata region, J. Hydrol., 351, 58-70, doi:10.1016/j.jhydrol.2007.11.041, 2008.

Sandholt, I., Rasmussen, K., and Andersen, J.: A simple interpretation of the surface temperature/vegetation index space for assessment of surface moisture status, Remote Sens. Environ., 79, 213-224, doi:10.1016/s0034-4257(01)00274-7, 2002.

Schaaf, C. B., Gao, F., Strahler, A. H., Lucht, W., Li, X., Tsang, T., Strugnell, N. C., Zhang, X., Jin, Y., and Muller, J. P.: First operational BRDF, albedo nadir reflectance products from MODIS, Remote Sens. Environ., 83, 135-148, 2002.

Shu, Y., Stisen, S., Jensen, K. H., and Sandholt, I.: Estimation of regional evapotranspiration over the North China Plain using geostationary satellite data, Int. J. Appl. Earth Obs. Geoinf., 13, 192206, doi:10.1016/j.jag.2010.11.002, 2011.

Stisen, S., Sandholt, I., Nørgaard, A., Fensholt, R., and Jensen, K. H.: Combining the triangle method with thermal inertia to estimate regional evapotranspiration - Applied to MSG-SEVIRI data in the Senegal River basin, Remote Sens. Environ., 112, 1242-1255, doi:10.1016/j.rse.2007.08.013, 2008.
Sun, D. and Kafatos, M.: Note on the NDVI-LST relationship and the use of temperature-related drought indices over North America, Geophys. Res. Lett., 34, L24406, doi:10.1029/2007GL031485, 2007.

Tang, B., Li, Z.-L., and Zhang, R.: A direct method for estimating net surface shortwave radiation from MODIS data, Remote Sens. Environ., 103, 115-126, doi:10.1016/j.rse.2006.04.008, 2006.

Tang, R., Li, Z.-L., and Tang, B.: An application of the Ts-VI triangle method with enhanced edges determination for evapotranspiration estimation from MODIS data in arid and semi-arid regions: Implementation and validation, Remote Sens. Environ., 114, 540-551, doi:10.1016/j.rse.2009.10.012, 2010.

Tang, R., Li, Z.-L., and Chen, K.-S.: Validating MODIS-derived land surface evapotranspiration with in situ measurements at two AmeriFlux sites in a semiarid region, J. Geophys. Res., 116, D04106, doi:10.1029/2010JD014543, 2011.

Toller, G. N., Isaacman, A., Kuyper, J., and Salomonson, V.: MODIS Level 1B Product User's Guide, Greenbelt, MD: NASA/Goddard Space Flight Center, 2006.

Vermote, E. F. and Kotchenova, S.: Atmospheric correction for the monitoring of land surfaces, J. Geophys. Res., 113, D23S90, doi:10.1029/2007JD009662, 2008.

Verstraeten, W., Veroustraete, F., and Feyen, J.: Assessment of Evapotranspiration and Soil Moisture Content Across Different Scales of Observation, Sensors, 8, 70-117, 2008.

Vinukollu, R. K., Wood, E. F., Ferguson, C. R., and Fisher, J. B.: Global estimates of evapotranspiration for climate studies using multi-sensor remote sensing data: Evaluation of three process-based approaches, Remote Sens. Environ., 115, 801823, doi:10.1016/j.rse.2010.11.006, 2011.

Wan, Z. M. and Dozier, J.: A generalized split-window algorithm for retrieving land-surface temperature from space, IEEE $\mathrm{T}$. Geosci. Remote Sens., 34, 892-905, 1996.

Wan, Z., Wang, P., and Li, X.: Using MODIS Land Surface Temperature and Normalized Difference Vegetation Index products for monitoring drought in the southern Great Plains, USA, Int. J. Remote Sens., 25, 61-72, 2004.

Wang, K., Li, Z., and Cribb, M.: Estimation of evaporative fraction from a combination of day and night land surface temperatures and NDVI: A new method to determine the Priestley-Taylor parameter, Remote Sens. Environ., 102, 293305, doi:10.1016/j.rse.2006.02.007, 2006.

Wang, W. and Liang, S.: Estimation of high-spatial resolution clearsky longwave downward and net radiation over land surfaces from MODIS data, Remote Sens. Environ., 113, 745-754, 2009.

Wang, W., Liang, S., and Augustine, J. A.: Estimating high spatial resolution clear-sky land surface upwelling longwave radiation from MODIS data, IEEE T. Geosci. Remote Sens., 47, 1559$1570,2009$. 